\title{
Immunologic Studies in Cow's Milk-induced Pulmonary Hemosiderosis
}

\author{
HARALDINE A. STAFFORD, STEPHEN H. POLMAR. ${ }^{(19)}$ AND THOMAS F. BOAT \\ Department of Pediatrics, Case Western. Reserve University, School of Medicine, Cleseland, Ohio, USA
}

\begin{abstract}
Summary
Antibodies to cow's milk proteins (CMP) were studied by radioallergosorbent tests to determine the quantity and immunoglobulin class of these antibodies in nine patients with precipitins to cow's milk. Three of these patients had pulmonary hemosiderosis (PII); in one other patient pulmonary hemosiderosis was suspected, but not proven. Three patients had nonhemosiderosis chronic lung disease and two had other diseases. Age-matched control subjects were also studied. The quantity and immunoglobulin class distribution of antibodies to CMP were similar in all patients; the quantity of anti-CMIP antibody was significantly greater in patients than in control subjects $(P<0.001)$. In addition, complement-fixing antibody to CMIP was not detected in either patients" or controls' sera.

Lymphocyte responses to CMIP were studied in three patients with PH, three individuals with other manifestations of milk hypersensitivity (positive controls), and nine negative control subjects. Patients and positive control subjects responded to CNIP with greater tritiated thymidine incorporation than the negative control subjects $(P<\mathbf{0 . 0 5})$. However, no significant difference in response to CMP was observed between the PII patients and the positive control subjects.

Antibodies to hunan lung tissue were studied in the sera of all patients with PII and two negative control subjects. Antibodies to human lung and rat lung were detected in one patient with PH.
\end{abstract}

\section{Speculation}

We have been unable to demonstrate any unique immunologic mechanism associated with milk-induced PH in the patients studied. However, these studies do not completely rule out the role of these immune mechanisms as it is possible that the antigen or antigens responsible for the relevant reactions may result from partial degradation of cow's milk protein and were not studied. Alternatively, increased availability of antigens may be important, which might result from excessive gastrointestinal absorption of intact cow's milk proteins. Furthermore, the possibility exists that unique antigens may be present in the lungs of patients with PH which cross-react either with antibodies to CMP or sensitized cells.

In 1962. Heiner et al. (8) reported the presence of multiple high titer milk precipitins in the sera of seven infants and children with chronic cough, recurrent lung infiltrates, wheezing. pulmonary hemosiderosis, persistent rhinitis, gastrointestinal symptoms, and anemia. Four of these patients described as having pulmonary hemosiderosis had hemoptysis. iron deficiency anemia, and iron-laden macrophages detected in gastric or bronchial washings or at lung biopsy (6). Precipitins to multiple constituents of cow's milk, positive intradermal immediate hypersensitivity reactions to various cow's milk proteins, recurrent otitis media, and growth retardation were additional fea- tures found throughout this group. Upon removal of cow's milk from the diet, the symptoms improved and, upon reintroduction of milk into the diet, the symptoms returned.

Holland et al. (9) observed not only a high incidence of chronic or recurrent pulmonary disease, but also recurrent upper respiratory tract infections associated with the presence of milk precipitins. Milk hypersensitivity was associated with respiratory disease, failure to thrive, ancmia, hepatomegaly, and splenomegaly and a causal relationship between milk and these symptoms was implicated because of improvement of these symptoms upon removal of milk proteins from the diet. Boitt at al. (3) studied children with typical features of Heiner's syndrome and confirmed the validity of the milk precipitin-pulmonary hemosiderosis syndrome and also noted that some of these patients also developed cor pulmonale secondary to upper airway obstruction.

However, the significance of milk precipitins in pulmonary hemosiderosis and respiratory disorders is controversial. Anderson and Schloss (2) in 1923 demonstrated that many chiddren fed cow's milk developed precipitating antibodies to milk proteins. Although milk precipitins were also observed in 50 () ir of patients with IgA deficiency (1), pulmonary hemosiderosis rarely occurs in this group. In addition, a few patients with pulmonary hemosiderosis without milk precipitins have improved when given a milk-free diet (7). These ohservations suggest that hypersensitivity to milk is important in the pathogenesis of pulmonary hemosiderosis, but that the milk precipitins themselves may not play a major role in this process.

To further investigate the possible immunologic mechanisms involved in the pathogenesis of milk-induced pulmonary hemosiderosis, studies of the yuantity, immunoglobulin class, and some biologic properties of the antibodies to cow's milk proteins were undertaken in patients with $(I)$ milk-indued pulmonary hemosiderosis, (2) nonhemosiderosis lung discase. (3) milk-induced gastrointestinal discase or chronic rhinitis, and (f) in normal individuals. In vitro lymphocyte responses to cow's milk proteins and antibodies to human lung tissue were also studied.

\section{MATERIALS AND METHODS}

\section{PATILNTS AND CONTROL SUBJECTS}

Nine children with one or more milk precipitins in their serum were studied. Three were definitely diagnosed as having milkinduced pulmonary hemosiderosis. In one additional child $(S C)$ the diagnosis of milk-induced pulmonary hemosiderosis is suspected, but remains in question because of the inability to demonstrate hemosiderin-laden macrophages in bronchial or gastric washings. Three other children had chronic pulmonary disease (nonhemosiderosis) and two had other diseases (i.e., gastrointestinal disease and upper respiratory infection). Clinical features and laboratory data relating to this group of children are summarized in Table 1 . Detailed clinical data on three of the patients $(L S, B B$, and $A E)$ with pulmonary hemosiderosis have 


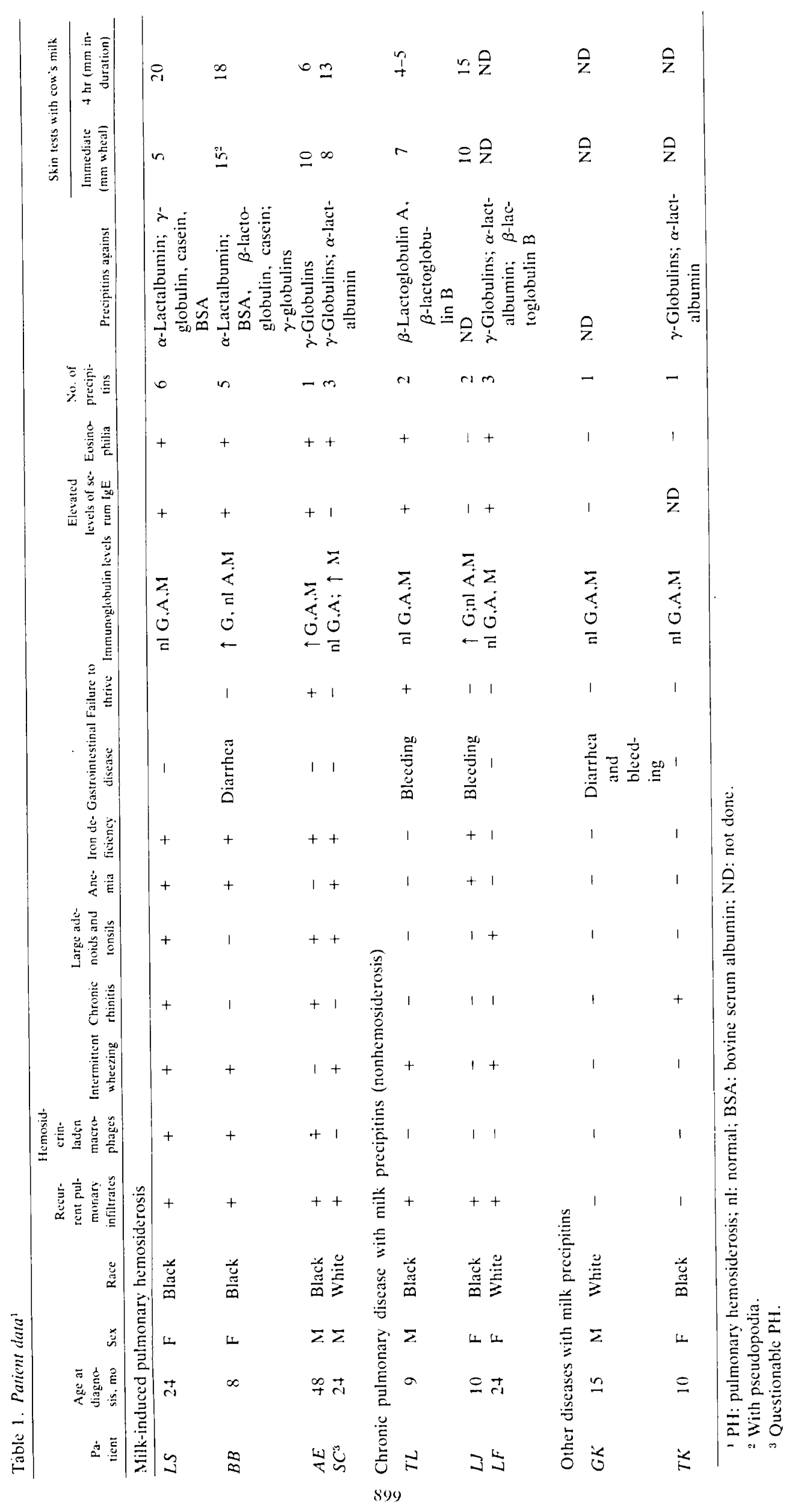


been presented previously (3). Precipitins against cow's milk proteins were detected by double diffusion analysis of serum. Macrophages in smears prepared from tracheal or gastric aspirates were stained for hemosiderin with potassium ferrocyanide. Immunoglobulins $\mathrm{G}, \mathrm{A}$, and $\mathrm{M}$ were studied by immunoelectrophoresis and quantitated by radial diffusion techniques. IgE was quantitated by radioimmunoassay (13). Nasal eosinophils, hemoglobin electrophoresis, and hematocrits were determined by the routine clinical laboratory tests. Skin testing was performed with $0.1 \mathrm{ml}$ filtered unpasteurized cow's milk containing 10.9 $\mathrm{mg} / \mathrm{ml}$ protein $(3)$.

Control subjects consisted of a group of 30 randomly selected age-matched children hospitalized for nonimmunologic, gastrointestinal, or pulmonary diseases. Seven adult laboratory and hospital personnel also served as control subjects.

Sera from patients and control subjects were stored at $-20^{\circ}$ before study. All serum samples studied were obtained when patients were on a milk-containing dict.

\section{PURIFIED IMAUNOGLOBULINS AND COW'S MILK PROTEINS}

Human $\operatorname{lgG}$ was obtained commercially (Miles Laboratories, Kankakee, Ill., fraction II powder) and further purified by elution from DEAE (diethylaminoethyl)-cellulose columns. IgA was prepared from human colostrum, IgM from sera of patients with Waldenstrom's macroglobulinemia, and lgE from serum of an $\mathrm{IgE}$ myeloma patient $(P S)$. These immunoglobulins were purified by preparative electrophoresis, DEAE-cellulose column chromatography, and gel filtration. The $\left(\mathrm{Fab}^{\prime}\right)_{2}$ fragment of $\mathrm{IgG}$ was prepared by pepsin digestion of purified human IgG. Purity of immunoglobulin preparations was established by immunoelectrophoresis and Ouchterlony double diffusion analysis.

Bovine $\gamma$-globulin, fraction II (BGG), was obtained from Schwarz/Mann (Orangeburg. N. Y.). Bovine serum albumin, fraction V (BSA), was obtained from Miles Laboratories. Cow's milk protein (CMP) preparations were prepared from raw cow's milk by centrifugation at $17,000 \mathrm{rpm}$ for $1 \mathrm{hr}$. The supernatant lipid layer was discarded and the defatted CMP was stored at $-20^{\circ}$ at a concentration of $10-13 \mathrm{mg} / \mathrm{ml}$.

\section{ANTISI:RA}

Antisera to CMP and human $\operatorname{IgG}, \operatorname{Ig} A, \operatorname{Ig} M, \operatorname{IgE}$, and the $\left(F^{\prime} b^{\prime}\right)_{2}$ fragment of $\lg G$ were prepared in rabbits. These antisera were made specific by appropriate absorption with human cord serum and purified immunoglobulin preparations. $\gamma$-Globulin fractions of rabbit anti-IgM, anti-IgE, and anti-CMP were prepared by elution from DEAE-cellulose. Specific anti-IgG, antiIgM, anti-IgA, and anti-(Fab'). were prepared by elution from Sepharose $4 B$ to which the appropriate immunoglobulin had been coupled by cyanogen bromide activation. A preparation of radioiodinated anti-human IgE (ND) was obtained from Pharmacia (Piscataway, N. J.). Specificity of these antibody preparations was established by immunoelectrophoresis and Ouchterlony double diffusion analysis. $\gamma$-Globulin fractions and specifically purified antibody preparations of anti-IgG, anti-IgA, antiIgMI, anti-(Fab'), and anti-CMP were radioiodinated using the iodine monochloride method (12). The $\gamma$-globulin fraction of anti-IgE was radioiodinated using the chloramine $\mathrm{T}$ method $(10)$.

\section{RADIOALLERGOSORBENT TEST (RAST)}

CMP was covalently linked to cyanogen bromide activated filter paper discs (Whatman no. 42) according to the method of Ceski and Lundkvist (4).

Ten to $50 \mu$ of serum or serum dilution in sodium phosphatebuffered saline (PBS), pH 7.2, was added to test tubes containing an antigen-coated filter paper disc. The final volume was adjusted to $0.2 \mathrm{ml}$ by the addition of PBS containing $0.5 \%$
Tween 20 and $5 \%$ normal rabbit serum. Reaction mixtures were incubated at room temperature for $3 \mathrm{hr}$ with constant shaking. After incubation the supernatant fluid was removed by aspiration and the filter paper dise washed three times with $2 \mathrm{ml}$ of PBS. Ten microliters of the appropriately diluted radioiodinated anti-immunoglobulin was added to the filter paper dise and the reaction mixture was adjusted to $0.2 \mathrm{ml}$ with PBS containing $0.5 \%$ Tween 20 and $5 \%$ normal rabbit serum. Reaction mixtures were incubated at room temperature for $18 \mathrm{hr}$ with shaking, after which the filter paper discs were again washed. The radioactivity of the antigen-coated dise was measured by counting in a Packard automatic gamma spectrometer. The level of nonspecific binding was determined by substituting buffer for serum or serum dilution in some reaction mixtures and processing these in an identical manner to the experimental tubes.

The specificity of the radioiodinated anti-immunoblobulins was established by binding studies using IgG-, IgM-, IgA-, IgE-, and BSA-coated discs. Less than $0.6 \%$ of the radioiodinated anti-immunoglobulin preparations bound to BSA-coated dises, whereas homologous antibody binding (e.g., anti-IgG to IgGcoated dises) ranged from 26-53\% depending upon the radioiodinated antibody preparation. Heterologous antibody binding (e.g. . anti-IgG to IgM-coated discs) was $6 \%$ or less.

The total quantity of antibody to CMP in a patient's or control's serum was expressed as the inverse of the dilution of the serum which bound $50 \%$ of the maximum amount of radioiodinated anti-immunoglobulin (anti-(Fab').2) that could be bound to CMP-coated discs. The $50 \%$ binding dilution was termed the $B_{50}$ of a serum. Maximal binding of the radioiodinated antiimmunoglobulin was determined by titration of serum from a patient with $\mathrm{PH}$ that had the highest titer of precipitating antibodies to CMP.

The immunoglobulin class to which a patient's anti-CMP belonged was determined by radioallergosorbent test as described above and the data were expressed as the mean percentage of anti-immunoglobulin counts bound minus nonspecific binding. Studies were performed in duplicate. The percentage of antiimmunoglobulin counts rather than raw counts were used to eliminate variation due to decay of the radioisotope (12.5) and to permit comparisons between serum samples studied at different times. Statistical comparisons between patient and control groups were carried out using the Student's t-test.

\section{MICROCOMPLEMINT FIXATION ASSAY}

The microcomplement fixation assay was carried out in a U-shaped well microtiter plate (Cooke Engineering). A tris(hydroxymethyl)aminomethane (0.1 M)-sodium chloride (0.14 M)-magnesium sulfate (0.015 M)-calcium chloride (0.01 M) buffer, pH 7.4 (Tris- $\mathrm{NaCl}$ ), was used for dilution of all reagents. The following reagents were added to each well of the microtiter plate: either 1 drop of appropriately diluted rabbit anti-serum to CNIP, patient's serum, or control serum; 1 drop of Tris- $\mathrm{NaCl}$ buffer; 1 drop of guinea pig serum (complement source) diluted $1 / 125$; and 1 drop of CMP or BGG at a concentration of $0.25 \mu \mathrm{g} / \mathrm{ml}$. The optimal concentrations of guineil pig serum, CMP, and BGG were determined by preliminary experiments. After slow shaking at room temperature for 5 min, the reaction mixtures were then incubated overnight at $4^{\circ}$. After incubation. 1 drop of sheep red blood cells that had been sensitized with rabbit hemolysin was added to each well. The reaction mixtures were then incubated at $37^{\circ}$ for $1 \mathrm{hr}$ and the reaction was terminated by placing the microtiter plates on ice for 10-15 min. The plates were then spun at $1,200 \mathrm{rpm}$ for $10 \mathrm{~min}$ and read according to the following criteria: complete hemolysis (no cells), 0 ; red cell ghosts, +1 ; few red cells remaining, +2 ; decreased red cell pellet, +3 ; full red cell pellet, +4 . Appropriate antigen, antibody, and complement controls were performed with each experiment. The gross complement fixation titer of a serum was considered to be the last dilution which 
gave a score of +2 or greater. A serum's anticomplementary activity was determined by titrating the serum with complement but in the absence of antigen. The difference between the gross complement fixing titer of the serum and its anticomplementary activity was recorded as its net complement-fixing antibody titer.

\section{LYMPHOCYTE STIMULATION ASSAY}

Mononuclear cell fractions containing $90 \%$ or greater lymphocytes were isolated by density gradient centrifugation using Ficoll-sodium metrizoate gradients $(14)$. The microlymphocyte stimulation assay was carried out in microtiter 11 culture plates (Falcon Plastics). To each well of the microculture plate, $1.5 \times$ $10^{5}$ mononuclear cells in $0.1 \mathrm{ml}$ RPMI- 1640 medium containing HEPES buffer, penicillin, streptomycin, and 20\% autologous plasma were added. CMP, BGG, or BSA was added to the wells at final concentrations of $50,100,500$, and $1000 \mu \mathrm{g} / \mathrm{ml}$. Lymphocyte responses to phytohemagglutinin, concanavalin $\mathrm{A}$, and pokeweed mitogen were also studied as a measure of cell viability and function. Cultures containing mitogens were incubated for 3 days whereas those containing antigens were incubated for 5 days at $37^{\circ}$. Five hours before harvesting the cultures, $0.5 \mu \mathrm{Ci}$ tritiated thymidine was added to each culture. Cultures were harvested using the automatic microlymphocyte harvester (Otto) Hiller, Madison, Wisc.). Tritiated thymidine incorporation into each culture was measured using a Searle automatic liquid scintillation system. All cultures were carried out in triplicate and data was expressed as the maximum mean counts per min in antigen-stimulated cultures minus the mean counts per min in unstimulated cultures, \pm 1 SD.

\section{INDIRECT IMIMUNOFLUORESCINCE}

Lung tissue from deceased children ()-6 years old without pulmonary discase was frozen in licuid nitrogen, cut in $4 \mu$ thick sections, and mounted on slides. Slides were washed twice for 10 min at room temperature with gentle shaking with $0.1+\mathrm{M} \mathrm{NaCl}$ $0.01 \mathrm{~N} \mathrm{KH}_{2} \mathrm{PO}_{4}$ buffer ( $\mathrm{NaCl}$ buffer), pH 7.2, and dried. Lung sections were overlayered with patient's or control serum, incubated in a moisture chamber at room temperature for $1 \mathrm{hr}$, and then washed twice in $\mathrm{NaCl}$ buffer. Fluoresceinated polyvalent anti-immunoglobulin (Hyland) was added to each section. The slides were incubated for at least 1 hr as before, washed twice in $\mathrm{NaCl}$ buffer, dried, mounted with a coverslip in 50 \%" glycerin. and stored at $4^{\circ}$. The slides were read within 48 hr using a fluoreseence microscope.

\section{RESUITS}

\section{QUANTITATION OF ANTIBODIES TO COW'S MILK PROTEINS AND} RELATIONSHIP TO MILK PRECIPITINS

The four patients with pulmonary hemosiderosis had $B_{50}$ values ranging from $15-160$ and had one to six milk precipitins. Those with nonhemosiderosis chronic lung disease had $B_{\text {an }}$ values from 30-64 and two to three milk precipitin lines. Those with gastrointestinal and upper respiratory discase had $B_{30}$ values of 10-12 and one milk precipitin. Seven patients who lacked milk precipitins served as negative control subjects and all had $B_{z, 1}$ values of less than 1 . There was a positive correlation $(r=$ $0.84, p<0.01)$ between the $B_{5, n}$ and the number of milk precipitins (I.ig. 1). Although patients with pulmonary hemosiderosis tended to have higher $B_{i, n}$ values and more milk precipitins than the other patients, there was considerable overlap.

\section{DETTERMINATION OF IMMUUNOGLOBULIN CLASS OI ANTIBODIES TO (MIP}

The nine patients with $B_{-w}$ values greater than 1 were studied by RAST to determine the immunoglobulin class of the antibodies to CMP. Because of a scarcity of L.S's serum, a $1 / 40$ serum dilution was used for the immunoglobulins $G$. M, and $A$ studies

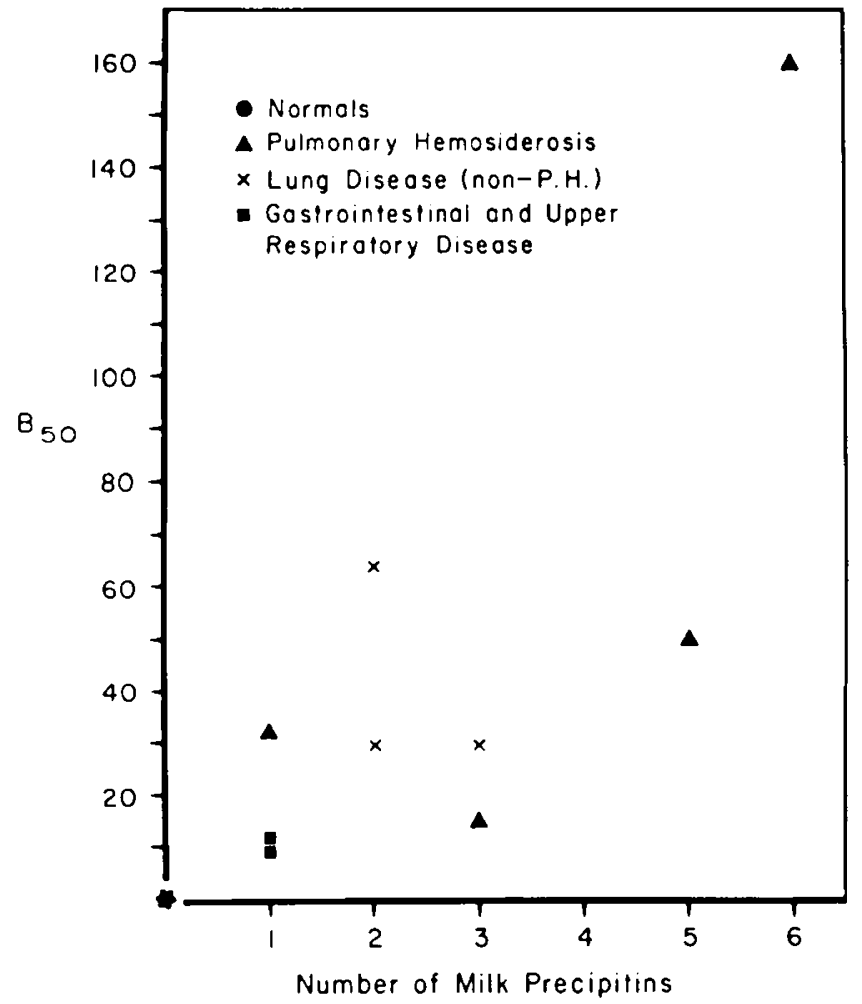

Fig. 1. Correlation of $50 \%$ binding difution $\left(B_{50}\right)$ values and number of milk precipitins.

and these results were not included in the statistical analysis for $\operatorname{IgG}, \operatorname{Ig} M$, and $\lg A$. For comparison, serum from 10 negative control subjects were studied for IgG, IgM, and IgA and serum from four negative control subjects were studied for lgl:. Results are given as mean percentage binding of each immunoglobulin minus mean nonspecific binding (lable 2).

As shown in Table 2, the sera of all patients with milk precipitins bound more anti-IgG $(p<0.0(0))$ and more anti-lgA $(p .<$ (0.0(01) than the control subjects indicating the presence of higher concentrations of $\operatorname{IgG}$ and $\lg A$ anti-CNP in the patient's sera. In contrast. there were no significant differences in mean percentage of binding of $\mathrm{lg} .1 \mathrm{l}$ and $\mathrm{IgE}$ between patients and control subjects. The difference in mean pereentage of binding between the pulmonary hemosiderosis patients and the other patients with milk precipitins was not significant for immunoglobulins $G, M, A$, and $\mathrm{L}$, whereas the difference in mean percentage of binding between the pulmonary hemosiderosis patients and control subjects was highly significant $(p<0.001)$. Binding of labeled anti-Igl: was detected only in the serum of one pulmonary hemosiderosis patient, $S C$.

Comparison of percentage of binding of different anti-immunoglobulin reagents is very similar to the original radioallergosorbent method of Wide. Bennich, and Johansson (15) and is only semiguantitative. Determination of $B_{3, n}$ values for each serum with each radioiodinated anti-immunoglobulin reagent might give more accurate guantitation of the class specificity of these antibodies to CMP. but this was not possible because of the limited amounts of patients" serat available for study.

\section{MICROCOMPLLEMENT FIXATION STUDILS}

RAST data had indicated that the immunoglobulin class distribution of anti-CMP was similar in all patients. We sought to determine whether a difference existed in the biologic function of anti-CMP in the sera of patients with pulmonary hemosiderosis compared to the anti-CMP antibodies in the serat of the other patients studied. Since the pulmonary lesions of pulmo- 
nary hemosiderosis resemble Arthus reactions, the ability of anti-CMP antibodies to fix complement was studied.

The ability of the patient's serum to fix complement upon the formation of antigen-antibody complexes with CMP and BGG was studied by the microcomplement fixation assay. All patients and normal (precipitin negative) control subjects showed no net complement-fixing (CF) antibody activity titers to CMP or BGG (gross milk titer minus anti-complementary titer (AC)), whereas the rabbit anti-CMP serum, used a positive control, consistently showed a 4 -fold or greater difference in $C F$ antibody titer with CMP or $B G G$ than without these antigens (AC titer). Consequently, no CF antibody can be demonstrated using native whole CMP or BGG as the antigen. AC titer of greater than 1/ 16 was detected in three of nine patients with milk precipitins and in two of six control subjects.

\section{LYMPHOCYTE RESPONSES TO COW'S MILK PROTEINS}

Lymphocyte responses to whole defatted CMP, BGG, and BSA were studied by microlymphocyte stimulation assay in three of the patients with pulmonary hemosiderosis, three individuals (termed positive control subjects) with past clinical histories of hypersensitivity to milk (purpura, gastrointestinal), and nine negative control subjects. Results are expressed as the mean maximum response in counts per min minus mean background counts per min \pm 1 SD to whole $C M P, B G G$, and $B S A$.

All patients with milk hypersensitivity responded to CMP with greater tritiated thymidine incorporation than did the negative control subjects $(P<0.05)$ (Table 3$)$. The response of pulmonary hemosiderosis patients does not differ significantly from the response of the positive control subjects $(P>0.8)$. However, the response of pulmonary hemosiderosis patientsto CMP does differ significantly $(P<0.05)$ from that of the negative control subjects. No statistically significant differences were observed with the response against $B G G$ and $B S A$.

\section{ANTIBODIES TO HUMAN LUNG TISSUE}

Antibodies to human lung tissue were sought in the sera of all patients with pulmonary hemosiderosis and in the sera of two control subjects using an indirect immunofluoreseence technique. The serum of one patient with pulmonary hemosiderosis $(B B)$ stained positively with human and rat lung tissue. Antibodies to rat or human lung tissue were not detected in the sera of the three other patients and the two control subjects.

\section{DISCUSSION}

We found no significant differences in the quantity or immunoglobulin class of the antibodies to CMP in sera from patients with pulmonary hemosiderosis as compared to patients with nonhemosiderosis lung disease, gastrointestinal or upper respiratory diseases who also had milk precipitins. IgE antibodies to CMP were present in only one of the patients studied $(S C)$. This observation is puzzling since all of the pulmonary hemosiderosis patients had elevated serum IgE levels while on a milk diet except for this patient. IVithin 2 months of the removal of milk from their diets, the patients had normal serum lgE levels (3). The $\mathrm{IgE}$ antibody in patients' sera may be directed against an antigen which develops in the course of digestion of CMP and is not present in native CMP preparations.

The ability to fix complement was not demonstrated in any of the human sera tested. The amount of anticomplementary activity was not restricted to any specific disease state. Consequently, we observed no significant difference in this biologic function between the anti-CMP antibodies of pulmonary hemosiderosis patients and those found in the other patients with milk hypersensitivity disorders without pulmonary hemosiderosis.

Lymphocyte stimulation responses to whole defatted CMP were demonstrated in all individuals studied with milk hypersensitivity, i.e., pulmonary hemosiderosis patients and positive control subjects with other manifestations of milk hypersensitivity. However, no difference in lymphocyte reactivity was observed between the pulmonary hemosiderosis patients and the control subjects with milk hypersensitivity. BGG and BSA did not elicit significantly different lymphocyte responses in the pulmonary hemosiderosis patients compared with the negative control subjects.

In addition, antibodies to homologous human lung tissue were not demonstrated in the sera of three of the four patients with pulmonary hemosiderosis.

The purpose of this study was to attempt to elucidate the immunopathologic mechanisms involved in milk-induced pulmonary hemosiderosis. Four types of immunologic reactions are thought to be responsible for hypersensitivity diseases in the lungs: type I (IgE dependent), type II (cytotoxic; tissue-specific antibody), type III (immunc complex), and type IV (cell mediated-delayed hypersensitivity) (5). Each of these immune reactions induces characteristic pathologic changes in the lungs. Each type of reaction has some unique characteristics; however, there is also some overlap as well, e.g., types II and III. By comparing the quantity, class and biologic function of the antibodies to CMP and cellular immune response to various cow's milk proteins in pulmonary hemosiderosis patients versus other patients, we attempted to find a property or mechanism unique to one disease state which was not operative in the others.

No immunologic mechanism studied was found to be unique to patients with milk-induced pulmonary hemosiderosis. This does not completely rule out these mechanisms as being operative in this disorder since it is possible that the antigen or antigens responsible for the relevant reaction may result from partial degradation of cow's milk protein and that these reactions could not be detected in our studies. In addition, if patients with milk-induced pulmonary hemosiderosis had antibodies to CMP that cross-reacted with unique antigens present in their lungs (type Il, cytotoxic antibodies), such antibodies might be absorbed in the lung and not be detectable in the patient's serum.

Table 2. Mean percentage of bindings of immunoglobulin class-specific antibodies in cow's milk proteins

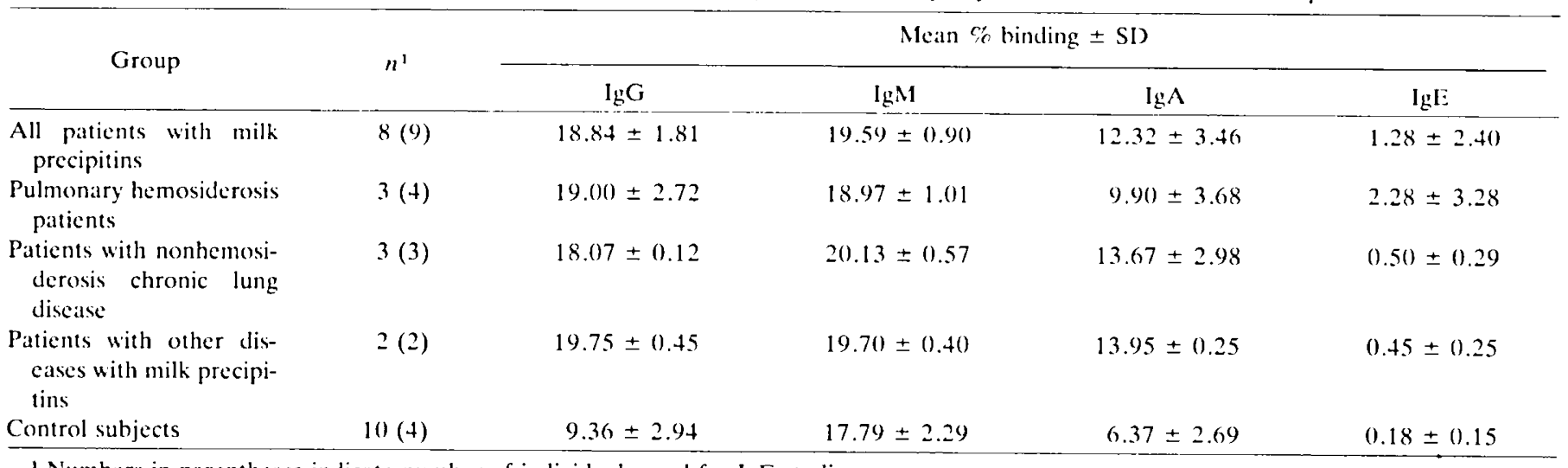

' Numbers in parentheses indicate number of individuals used for IgE studies. 
Table 3. In vitro lymphocyle responses to cow's milk proteins (C.MP)'

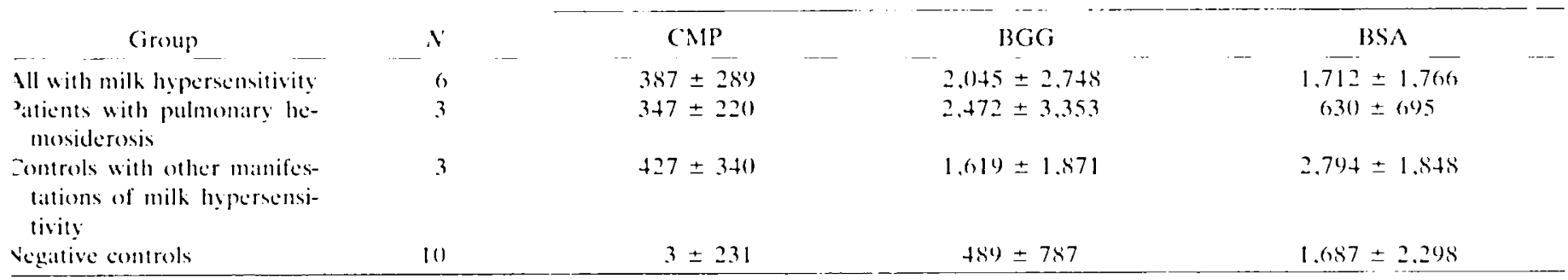

' BGG: bovine $\gamma$-globulin (fraction 11); BSA: bovine serum albumin.

Unfortunatcly, lung tisste from our patients was not available for immunofluoreseent studies.

Alternatively. the availability of antigen might play a crucial role in determining whether or not pulmonary hemosiderosis will develop. It is possible that excessive absorption of cow's milk protein from the galstrointestinal tract may occur in patients with Heiner's syndrome providing the necessary antigen for these immunologic reactions to occur.

All of these possibilities require investigation since the immunopathogenesis of milk-induced pulmonary hemosiderosis is still unknown.

\section{CONCLUSION}

Antibodies to (NAP were studied by RAST to determine the quantity and immunoglobulin class of these antibodies in sera of (1) four patients with milk-induced Pll, (2) three with chronic lung disease without PH, and (3) two with other disorders with milk precipitins as well ats in the sera of $(f) 10$ age-matched randomly selected control subjects. The quantity and immunoglobulin class distribution of antibodies to CNP Were similar in all patients, $i$ e. . antibodies to CMP were predominently of the $\operatorname{IgG}$ and IgA classes. The quantity of anti-CMP antibody was significantly greater in patients than in control subjects $(P<$ $0.0(01)$. In addition, CF antibody to CMPP was not detected in either patients or controls' sera.

In vitro lymphocyte responses to CMP. BGG, and BSA were studied in (l) three patients with PH. (2) three individuals with other manifestations of milk hypersensitivity (positive control subjects), and (3) nine negative control subjects. Patients and positive control subjects responded to CMP with greater tritiated thymidine incorporation than did the negative control subjects $\left(I^{\prime}<0.05\right)$. However, no significant difference in response to CMP was observed between the Pll patients and the positive controls $(P>0.8)$. No statistically significant differences were observed with the responses against $B G G$ and $B S A$ between all groups studied.

Antibodies to normal human lung tissue were studied in the sera of four pattients with $\mathrm{PH}$ and two negative control subjects. Antibodies to human and rat lung were detected in one patient with PII.

\section{RIFIRENCIS AND NOTISS}

1. Ammann, A. J., and Hong, R.: Selective IgA deficiency: Presentation of 30 cales and at review of the literature. Medicine, 50: 223 (197!).

2. Anderson. A. F.. and Schloss. (). M1. Allergy to cows milk in infants with nutritional disorders: A preliminary report. Amer. J. Dis. Child.. 26: 451 (1923)

3. Boat. T. F., at al.: Hyperreactivity to cow's milk in young children with pulmonary hemosiderosis and cor pulmonale secondary to nasopharyngeal obstruction. J. Pecliat.. 87: 23 (1975).

4. Ceska, M., and Lundkvist, U.: A new and simple radiosmmunoassaly method for the determination of $\mathrm{I}[\mathrm{E}$. Immunochemistry, 9: 1021 (1972).

5. Coumbs, R. R. A.. and Gill, P. G. H.: Classification of allergic reactions respensible for clinical hypersensitivity and disease. In: Clinical Aspects of Immunology, p. 575 (Blackwell Scientific Publications, Oxford, 1968 ).

6. Heiner, D. C.: Pulmonary hemosiderosis. In: E. L. Kendig, Jr.: Pulmonary Disorders of the Respiratory Tract in Children, Vol. 1, p. 345 (W. B. Saunders (o.. Philadelphia, 1972).

7. Heiner, D). C.: Pulmonary Dionders, Vol, 1, p. 376 (W. B. Satunders, Philadelphia, 1972).

8. Heiner. D. C.. Sear, J. W., and kniker, W. T.: Multiple precipitins to cows milk in chronic respiratury disease. Amer. J. Dis. Child., 103: 40 (1962)

9. Holland, N. H., Hong, R., Davis, N. C.. and West. (. D).: Significance of precipitating antibodies to milk proteins in the serum of infants and children. J. Pediat., 6/: $181(1962)$.

10. Hunter, W. M... and Girenwood, F. C.: Natture, 194: 495 (1962).

11. I.evine, I..: Microcomplement tixation. In: D. M. Weir: Handhook of Experimental Immunology, p. 707 (Blackwell Scientific Publications. Oxford. (967).

12. McFarlane A S : Mammalian Protein Mctabolism, 1: 331 (196-4).

1.3. Polmar. S. H. Waldmann. T. A.. and Terry, W. D.: A comparison of three radiommunoassay techniques for the measurement of serum lgl:. J. Immunol.. $110: 1253(1973)$.

14. Thorsby, $: \ldots$ and Bratalic, A.: A rapid method for preparation of pure lymphocyte suspensions. In: P. I. Teresaki: Histocompatibility Testing. 1970. p. 655-656 (Munkegaturd, Copenhagen, 1970).

15. Wide, I... Bennich, 11., and Johansson. S. G. O.: Diagnosis of allergy by an in vitro test for allergen antibodies. Lancet, ii: 1105 (1967).

16. Most of this study was done retrospectively, consequently, informed consent was not necessary. Verbal informed consent was ohtained for the remainder of the study.

17. H. A. Stafford is recipient of a Northern Ohio I.ung Association Student Resciatch Fellowship.

18. This rescarch was supported by grants from the Cystic Fibrosis Foundation (Cleveland Chapter) and the National Institutes of llealth (III. 13885 and Hil. $06(0)(0)$.

19. Requests for reprints should be addressed to: S. H. Polmat, Ph.D., M.D.. Division of Pediatric lmmunology. Rainbow Bathes and Children Hospital, 2101 Adelbert Rd.. Cleveland. Ohio $4+106$ (USA)

20. Received for publication July 25, 1976.

21. Accepted for publication Fibruary 9, 1977. 